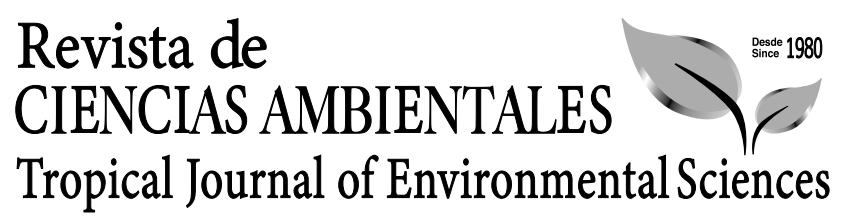

Revista de Ciencias Ambientales (Trop J Environ Sci) e-ISSN: 2215-3896

(Enero-Junio, 2021) . Vol 55(1): 345-359 DOI: https://doi.org/10.15359/rca.55-1.10

Open Access: www.revistas.una.ac.cr/ambientales e-mail: revista.ambientales@una.ac.cr

\title{
¿Cuán veraz es la célebre alocución conservacionista del Jefe Seattle?
}

\author{
How truthful is Chief Seattle's famous conservation-oriented speech?
}

\author{
Luko Hilje ${ }^{1}$
}

\section{Resumen}

Por muchos años se ha debatido la legitimidad de una conmovedora alocución conservacionista atribuida al Jefe Seattle, la cual data de 1854. Sin embargo, fue escrita en 1970 para la serie televisiva Home por el guionista Ted Perry, inspirado en un discurso de dicho líder indígena, que fue reconstruido y publicado por Henry A. Smith en 1887. Para despejar cualquier duda acerca del contenido exacto y la paternidad de tan polémico texto, aquí se incluyen las versiones de Smith y Perry — traducidas al español por una misma persona, para evitar cualquier sesgo-, y se les ubica en el contexto histórico en que aparecieron.

Palabras clave: Amerindios; conservación, ecología; Henry A. Smith; naturaleza, Ted Perry.

\begin{abstract}
The legitimacy of a touching conservation-oriented speech attributed to Chief Seattle, dating from 1854, has been debated for many years. Nevertheless, it was written in 1970 for the television series Home by screenwriter Ted Perry, inspired by a speech by Chief Seattle which was reconstructed and published by Henry A. Smith in 1887 . To dispel any doubt about the exact content and paternity of such a controversial text, the versions of Smith and Perry are included here - translated into Spanish by the same person, to avoid any bias-, and they are placed in the historical context in which they appeared.
\end{abstract}

Keywords: Conservation; ecology; Henry A. Smith; native Americans; nature; Ted Perry.

\section{Introducción}

Hace 20 años publicamos en un diario costarricense un artículo referido a la bella alocución intitulada Después de todo, quizás seamos hermanos, que data de 1854 y es atribuida a un indígena norteamericano conocido como Jefe Seattle (Hilje, 2000, p. 14A). En este comentábamos que nos la topamos por primera vez en 1980 y, por su valor testimonial y lírico, la atesoramos "para sentir las palpitaciones de esa sabia y reposada voz, emergida del contacto más puro y primigenio con el mundo natural".

Sin embargo, años después sufriríamos una gran decepción, al leer un artículo del editor de una revista ambientalista estadounidense (Anónimo, 1989), que demostraba que este líder indígena no era el autor de dicho texto, sino el guionista Ted Perry, quien en 1970 lo escribió para la película Home, aunque sí se inspiró en un supuesto discurso del Jefe Seattle.

1 Profesor emérito. Centro Agronómico Tropical de Investigación y Enseñanza (CATIE). Turrialba, Costa Rica. luko@ice.co.cr

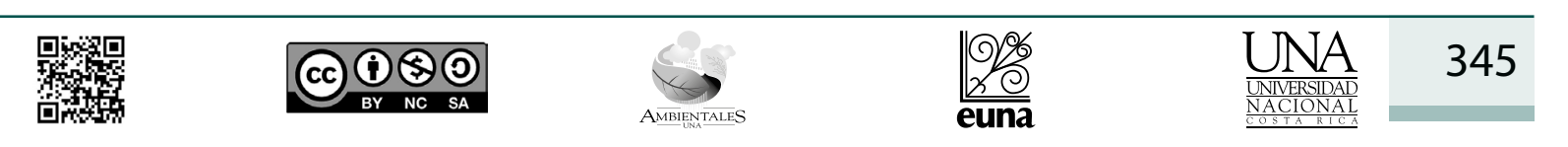




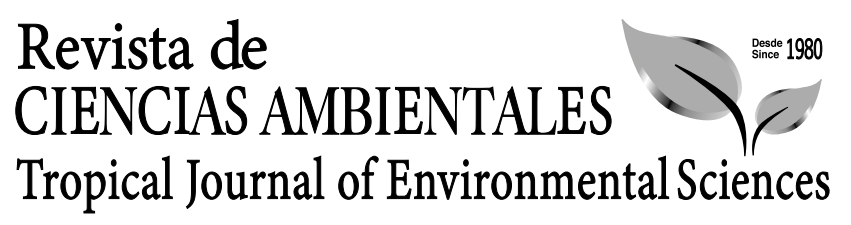

Revista de Ciencias Ambientales (Trop J Environ Sci) e-ISSN: 2215-3896 (Enero-Junio, 2021) . Vol 55(1): 345-359 DOI: https://doi.org/10.15359/rca.55-1.10 Open Access: www.revistas.una.ac.cr/ambientales e-mail: revista.ambientales@una.ac.cr

Hilje L.

Acogiendo sus juicios, ahí aclarábamos que Perry "nunca pretendió crear una farsa, sino que fue el productor de Home quien, para lograr mayor fuerza emotiva, no dio el respectivo crédito a Perry en la cinta. Este es el origen de este engaño impensado, que se ha propagado mundialmente" (Hilje, 2000, p. 14A). Con ello dimos por esclarecida esta situación, y no nos preocupamos más por el asunto.

No obstante, en tiempos recientes, cuando preparábamos una antología acerca de la presencia de la naturaleza en algunos textos literarios (poemas, cuentos, novelas, ensayos, relatos de viajeros, etc.), decidimos incluir el documento de Perry en dicho libro. Fue por ello que contactamos a este escritor, para tener plena certeza de la paternidad del texto. Su pronta y gentil respuesta, que data del 27 de diciembre de 2016, fue que podríamos consignar la siguiente frase aclaratoria: "Escrito por Ted Perry, e inspirado en un discurso atribuido al Jefe Seattle, el cual fue publicado por Henry Smith en 1887".

En realidad, el objetivo de este artículo no es polemizar o alimentar el debate acerca del origen y el contenido del texto; sobre esto hay una gran cantidad de información, incluso en Internet. Más bien, se trata de dar a conocer en español el contenido original de los dos documentos clave, para así entender mejor esta situación. Hasta ahora se disponía solamente de varias traducciones del texto de Perry, algunas incompletas - por motivos que ignoramos-, otras más o menos alteradas, además de que algunos matices líricos han dado pie a que no haya plena coincidencia entre ambas versiones.

Por tanto, para subsanar esto y, a la vez, poder comparar a cabalidad la versión de Perry con el texto original, optamos por recurrir a una traductora profesional — de inglés y alemán-, Silvia Kruse Quirós, quien además es escritora, lo que le permite captar y verter a nuestro idioma los abundantes y hermosos giros y recursos líricos propios de los dos textos. De esta manera, resulta posible percibir mejor los paralelismos y las divergencias que hay entre ambos escritos, tan indisolublemente unidos.

\section{El discurso del Jefe Seattle}

Antes de transcribir aquí el contenido del texto original, es importante ubicar el contexto histórico y geográfico en que surgió.

Corría el año 1854, y por entonces el presidente de EE. UU. era Franklin Pierce (Figura 1a). De infausta memoria para los países centroamericanos, como genuino representante de los intereses de los estados sureños de EE. UU. - que promovían la esclavitud-, inicial y subrepticiamente favoreció al ejército filibustero de William Walker (Obregón, 1991), que tantas pérdidas humanas y económicas causó a dichos países, y en particular a Costa Rica y Nicaragua. Con el apoyo económico y logístico de los sureños, al mando de una tropa de filibusteros, Walker quien en julio de 1856 se convertiría en presidente de Nicaragua- desembarcó en dicho país en junio de 1855, con la premeditada intención de instaurar la esclavitud en Centroamérica, así como de anexar sus países a los EE. UU., para sumar nuevos estados a los confederados.

\begin{tabular}{|c|c|c|c|c|c|}
\hline 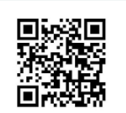 & (c) (i) & $\underset{\text { AMBIINTALS }}{\infty}$ & $\frac{\mid \% \%}{\text { euna }}$ & $\frac{\text { UNA }}{\frac{\text { UNILERIDAD }}{\text { NACIONAL }}}$ & 346 \\
\hline
\end{tabular}




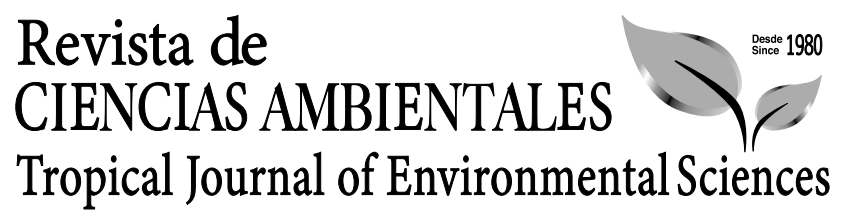

Revista de Ciencias Ambientales (Trop J Environ Sci) e-ISSN: 2215-3896 (Enero-Junio, 2021) . Vol 55(1): 345-359 DOI: https://doi.org/10.15359/rca.55-1.10 Open Access: www.revistas.una.ac.cr/ambientales e-mail: revista.ambientales@una.ac.cr

Hilje L.

Asimismo, en dicho contexto expansionista, pero al interior de los EE. UU., había un interés manifiesto en adquirir territorios pertenecientes a los indígenas nativos. Un testigo presencial de estos intentos fue el médico y escritor Henry A. Smith (1830-1915) (Figura 1b), uno de los primeros pobladores blancos de Seattle -en el actual estado de Washington-, quien después incursionaría en el mundo de la política.

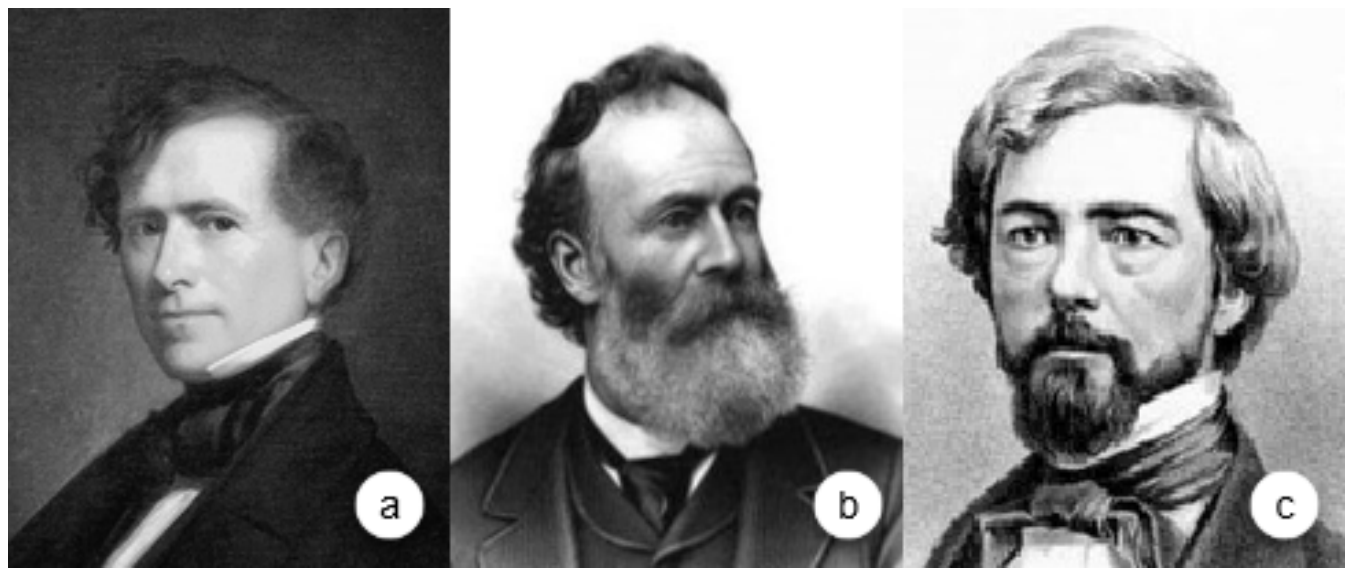

Figura 1. Franklin Pierce (a), Henry A. Smith (b) e Isaac Stevens (c).

Figure 1. Franklin Pierce (a), Henry A. Smith (b) e Isaac Stevens (c).

En efecto, al parecer en enero de 1854, Smith tuvo la oportunidad de escuchar un discurso del Jefe Seattle, Seathl, Sealth o See-ahth, a propósito de la llegada ahí de Isaac Stevens (Figura 1c) como delegado gubernamental; este indígena, nacido en 1786 y fallecido en 1866, era el líder de las etnias Suquamish y Duwamish. Smith tomó abundantes apuntes, que le permitieron tratar de reconstruir un texto aproximado de lo que dijo, el cual publicó en el periódico Seattle Sunday Star (29-X-1887, p. 10); nótese, eso sí, que no lo hizo sino hasta 33 años después. Por fortuna, dicho artículo fue recopilado en Gifford (2015), en un libro dedicado por completo a esta controvertida cuestión.

Es decir, no se trata de una carta enviada por el líder indígena al presidente Pierce - como se ha dicho en algunas publicaciones-, sino de un texto bastante minucioso, que dice así:

El viejo Jefe Seattle era el indio más grande que vi jamás y, con mucho, el de apariencia más noble. Llegaba al metro ochenta en sus mocasines, era de hombros anchos, tórax amplio y resonante, y bien proporcionado (Figura 2). Tenía unos ojos muy grandes, inteligentes, expresivos, amistosos cuando reposaban, que reflejaban fielmente las variaciones del humor de la gran alma que se asomaba por ellos. Por lo general, solemne, silencioso y digno, en las grandes ocasiones se movía por entre las multitudes como un titán entre liliputienses: su palabra más mínima era ley.

\begin{tabular}{|c|c|c|c|c|c|}
\hline 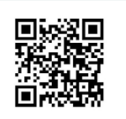 & (c) () () () & $\underset{\text { AMBIENTILS }}{3}$ & $\frac{1 \%}{2 \%}$ & 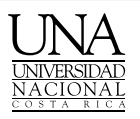 & 347 \\
\hline
\end{tabular}




\section{Revista de CIENCIAS AMBIENTALES Tropical Journal of Environmental Sciences}

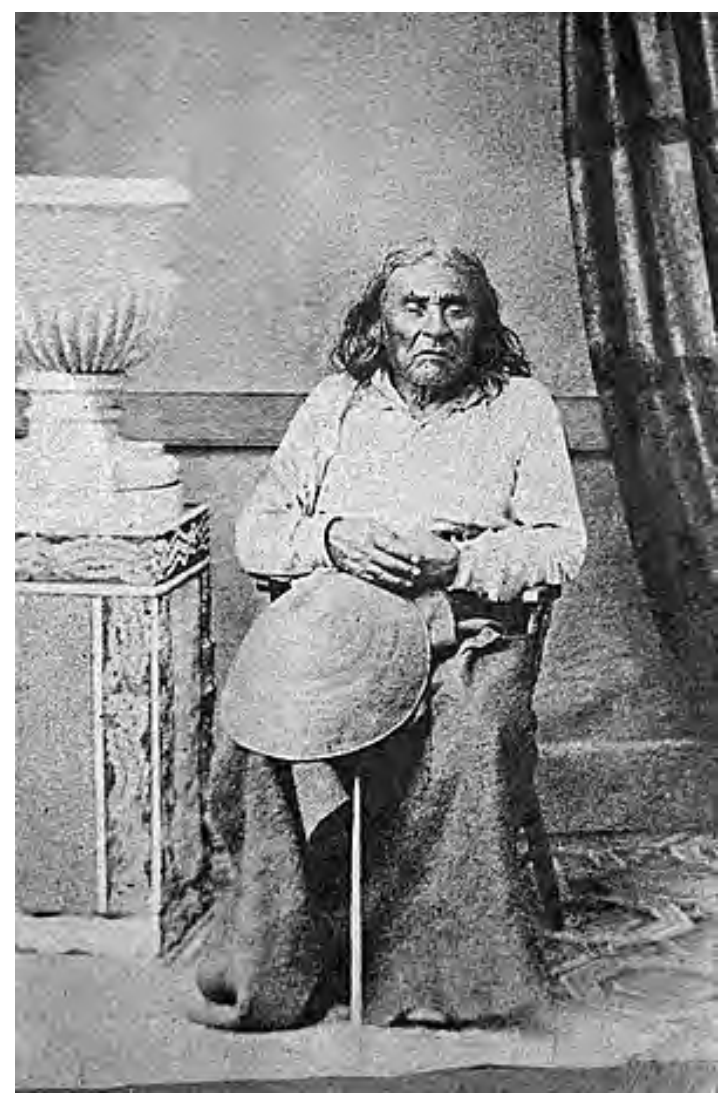

Figura 2. El Jefe Seattle en la ancianidad.

Figure 2. Chief Seattle in old age.

Cuando se levantaba a hablar en una asamblea o a dar un consejo, todos los ojos lo volvían a ver, y de sus labios rodaban frases de sonido profundo, sonoras y elocuentes como los truenos incesantes de las cataratas que brotan de fuentes inagotables, y su estampa magnífica era tan noble como la del más cultivado jefe militar al mando de las fuerzas de un continente. $\mathrm{Ni}$ su elocuencia, ni su dignidad, ni su gracia eran adquiridas. Eran tan propias de su virilidad, como las hojas y los capullos de las flores del almendro.

Su influencia era maravillosa. Podría haber sido un emperador, pero todos sus instintos eran democráticos y gobernaba a sus leales súbditos con amabilidad y benignidad paternal.

Se sentía halagado cuando los hombres blancos le prestaban atención, y nunca tanto como cuando lo sentaban a sus mesas; en esas ocasiones se manifestaban más que en ningún otro momento sus instintos de genuino caballero.

\begin{tabular}{|c|c|c|}
\hline 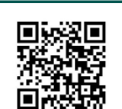 & (c) (i) () (2) (2) & 348 \\
\hline
\end{tabular}




\section{Revista de CIENCIAS AMBIENTALES Tropical Journal of Environmental Sciences}

Revista de Ciencias Ambientales (Trop J Environ Sci) e-ISSN: 2215-3896 (Enero-Junio, 2021) . Vol 55(1): 345-359 DOI: https://doi.org/10.15359/rca.55-1.10 Open Access: www.revistas.una.ac.cr/ambientales e-mail: revista.ambientales@una.ac.cr

Cuando el gobernador [Isaac] Stevens llegó a Seattle por primera vez y les dijo a los nativos que había sido designado Comisionado de Asuntos Indígenas para el Territorio de Washington, estos le dieron una calurosa bienvenida frente a la oficina del Dr. [David Swinson] Maynard, cerca de la costa, en la calle principal. Las canoas hormigueaban en la bahía y a la orilla del mar se alineaba una oscura masa de humanidad viviente, que se mecía y se retorcía hasta que empezó a rodar por encima de la inmensa multitud la voz de trompeta del viejo Jefe Seattle, cual si fuera la diana sobrecogedora de un bombo, y el silencio fue tan instantáneo y tan perfecto como el que sigue al trueno en un cielo despejado.

El Dr. Maynard le presentó el gobernador a la multitud nativa: este empezó inmediatamente a explicarles su misión entre ellos, en un estilo conversacional y simple, misión tan bien sabida que no necesita recapitulación. En cuanto este se sentó, se levantó el Jefe Seattle con toda la dignidad de un senador que lleve sobre los hombros la responsabilidad de una gran nación. Colocó una mano sobre la cabeza del gobernador, con el índice de la otra señaló lentamente el cielo y, en un tono impresionante y solemne, comenzó su memorable alocución:

Puede ser que cambie el cielo de allá arriba que, por incontables siglos, ha llorado lágrimas de compasión sobre nuestros padres, y que nos parece inmutable y eterno. Hoy está despejado: mañana, cubierto de nubes. Mis palabras son como las estrellas que nunca se ponen. El gran jefe Washington puede fiarse de lo que dice Seattle, con la misma seguridad con que nuestros hermanos cara pálida confían en el retorno de las estaciones. [En esos días tempranos, los indios pensaban que George Washington todavía estaba vivo. Sabían que era el nombre de un presidente, y cuando oían del presidente "de" Washington, confundían el nombre de la ciudad con el nombre del jefe reinante. También, pensaban que el rey Jorge todavía era el monarca de Inglaterra, porque los comerciantes de la Bahía de Hudson se referían a sí mismos como "hombres del rey Jorge". La Compañía era lo suficientemente astuta como para no aclarar este engaño inocente, porque los indios les tenían más respeto del que les habrían tenido si hubieran sabido que Inglaterra estaba regida por una mujer. Algunos de nosotros ya estamos más al tanto].

El hijo del jefe blanco dice que su padre nos envía saludos amistosos y de buena voluntad, lo cual es muy amable: sabemos que, en cambio, tiene poca necesidad de nuestra amistad, porque es mucha su gente. Son como el pasto que cubre las vastas praderas, mientras que mi gente es poca y más bien evoca los árboles dispersos de un llano recién barrido por la tormenta.

El gran, y supongo que también buen, jefe blanco, nos manda a decir que desea comprar nuestras tierras y que está dispuesto a dejarnos suficientes como para que vivamos confortablemente. Esto parece realmente generoso, pues el hombre rojo ya no tiene derechos que él necesite respetar, y la oferta también puede ser sabia, porque ya nosotros no necesitamos un gran país.

\begin{tabular}{|c|c|c|c|c|c|}
\hline 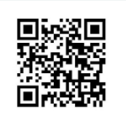 & (c) (i) & $\underset{\text { AMBIINTALS }}{\infty}$ & $\frac{O \%}{\frac{O}{2}}$ & $\frac{\text { UNA }}{\frac{\text { UNILERIDAD }}{\text { NACIONAL }}}$ & 349 \\
\hline
\end{tabular}




\section{Revista de CIENCIAS AMBIENTALES Tropical Journal of Environmental Sciences}

Revista de Ciencias Ambientales (Trop J Environ Sci) e-ISSN: 2215-3896

(Enero-Junio, 2021) . Vol 55(1): 345-359 DOI: https://doi.org/10.15359/rca.55-1.10

Open Access: www.revistas.una.ac.cr/ambientales e-mail: revista.ambientales@una.ac.cr

Hubo un tiempo en que nuestra gente ocupaba todas las tierras, de la misma manera en que las olas de un mar encrespado por el viento cubren el suelo pavimentado de conchas. Pero ese tiempo se extinguió hace mucho y la grandeza de las tribus está ya casi sumida en el olvido. No voy a lamentarme por nuestra decadencia prematura, ni les voy a reprochar a mis hermanos cara pálida el haberla acelerado, pues a nosotros también nos puede corresponder algo de culpa.

Cuando nuestros jóvenes se enojan por un agravio, real o imaginario, y se desfiguran la cara con pintura negra, sus corazones también se desfiguran y se vuelven negros, y su crueldad es implacable, sin límites, y nuestros ancianos no los pueden contener.

Esperemos, sin embargo, que las hostilidades entre el hombre rojo y sus hermanos cara pálida no retornen nunca. Tendríamos todas las de perder, y ninguna ganancia.

Es cierto que nuestros jóvenes consideran que en sí la venganza ya es ganancia, incluyendo el costo de las propias vidas, pero los ancianos, quienes se quedan en la casa en tiempo de guerra, $y$ las ancianas, quienes tienen hijos que perder, tienen mejor idea que ellos.

Nuestro gran padre en Washington, porque presumo que ahora es nuestro padre tanto como el de ustedes, ya que Jorge corrió al norte sus fronteras, nuestro gran y buen padre, digo, nos manda a decir con su hijo, de quien no dudo que también es un gran jefe entre su gente, que nos va a proteger si hacemos lo que desea. Sus bravos ejércitos van a constituir una barrera fortísima también para nosotros, y sus magníficos barcos de guerra van a llenar nuestros puertos, de modo que nuestros enemigos de siempre, los tsimshian y los haida, lejos hacia el norte donde habitan, ya no podrán asustar a nuestras mujeres ni a nuestros ancianos. Él será entonces nuestro padre y nosotros seremos sus hijos.

¿Será posible que esto suceda alguna vez? El dios de ustedes ama a su gente y odia a la mía, abraza con amor al hombre blanco y lo conduce amorosamente como un padre al hijo infante, pero desampara a sus hijos rojos; cada día vuelve más fuerte a la gente de ustedes, de manera que pronto llenará la tierra, mientras que mi gente mengua como marea que rápidamente se retira y no vuelve nunca más. El dios del hombre blanco no puede amar a sus hijos rojos pues, si lo hiciera, también los protegería. Pero parecen huérfanos que no pueden buscar ayuda en ninguna parte. ¿Cómo, entonces, podemos convertirnos en hermanos? ¿Cómo puede su padre convertirse en el nuestro y traernos prosperidad, y despertar en nosotros los sueños de una grandeza que retorna?

Nos parece que el dios de ustedes es parcial. Llegó aquí con el hombre blanco. Nunca lo habíamos visto, ni siquiera habíamos oído nunca su voz; le dio leyes al hombre blanco, pero no

\begin{tabular}{|c|c|c|}
\hline 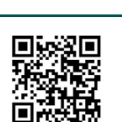 & (c) (i) (\$) (2) & 350 \\
\hline
\end{tabular}




\section{Revista de CIENCIAS AMBIENTALES Tropical Journal of Environmental Sciences}

Revista de Ciencias Ambientales (Trop J Environ Sci) e-ISSN: $2215-3896$

(Enero-Junio, 2021) . Vol 55(1): 345-359 DOI: https://doi.org/10.15359/rca.55-1.10

Open Access: www.revistas.una.ac.cr/ambientales e-mail: revista.ambientales@una.ac.cr

tuvo ni una sola palabra para sus hijos rojos, cuyos abundantes millones llenaban este vasto continente como las estrellas el firmamento. No: somos dos razas diferentes y así debemos permanecer para siempre. Tenemos muy poco en común: las cenizas de nuestros antepasados son sagradas y el suelo donde descansan es sagrado, mientras que ustedes se alejan de las tumbas de sus padres sin ningún pesar aparente. Para que no la olviden, la religión de ustedes fue escrita en tablas de piedra por el dedo de hierro de un dios iracundo. El hombre rojo nunca ha podido ni recordarla, ni entenderla.

Nuestra religión está compuesta por las tradiciones de nuestros antepasados, por los sueños que el gran Espíritu les otorga a nuestros viejos, y por las visiones de los líderes de nuestras tribus, y está escrita en los corazones del pueblo.

En cuanto pasan el portal de la tumba, los muertos de ustedes los dejan de amar, a ustedes tanto como a los hogares en que nacieron. Y se van muy lejos, más allá de las estrellas, por lo que pronto son olvidados y no retornan nunca. Nuestros muertos nunca olvidan el hermoso mundo que les otorgó el ser. Siguen amando los ríos serpenteantes, las montañas majestuosas $y$ los valles escondidos, y añoran siempre todo con el más tierno afecto, inclinados sobre los que viven con el corazón solitario, y vuelven a menudo a visitarlos y a reconfortarlos.

El día y la noche no pueden coexistir. El hombre rojo siempre ha huido cuando se aproxima el hombre blanco, de la misma forma en que, en las laderas, los rocíos cambiantes huyen del sol ardiente de la mañana.

Sin embargo, su propuesta parece justa, y pienso que mi pueblo la va a aceptar y se va a retirar a la reserva que usted les ofrece, y vamos a habitarla aparte y en paz, ya que las palabras del gran jefe blanco parecen ser la voz de la naturaleza, hablándole a mi gente desde una oscuridad espesa que se acumula rápidamente a su alrededor, como la niebla densa que flota tierra adentro desde el mar de medianoche.

Apenas si importa dónde pasemos lo que queda de nuestros días.

No nos quedan muchos. Y la noche de los indios promete ser oscura. No hay ninguna estrella luminosa que se cierna sobre el horizonte. Los vientos de voz triste se lamentan en la distancia. Una severa némesis de nuestra raza le sigue el rastro al hombre rojo y, doquiera que vaya, oirá acercarse los pasos inexorables de la destructora, y deberá prepararse para su amargo destino, como la cierva herida que oye acercarse los pasos del cazador. Unas cuantas lunas más, unos cuantos inviernos, y ni uno solo de los integrantes de las muchedumbres poderosas que una vez llenaron esta ancha tierra y que hoy recorren estas vastas soledades en bandas fragmentadas,

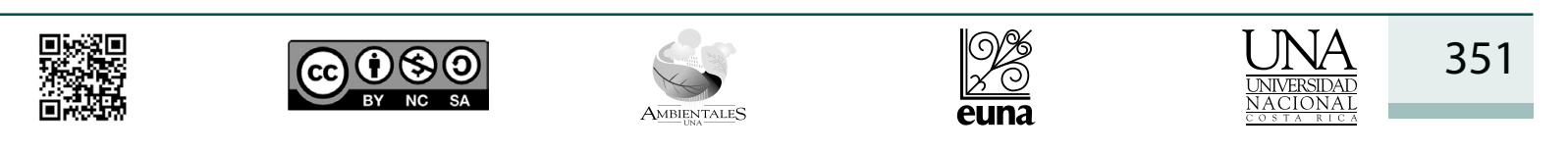




\section{Revista de CIENCIAS AMBIENTALES Tropical Journal of Environmental Sciences}

Revista de Ciencias Ambientales (Trop J Environ Sci) e-ISSN: $2215-3896$

(Enero-Junio, 2021) . Vol 55(1): 345-359 DOI: https://doi.org/10.15359/rca.55-1.10

Open Access: www.revistas.una.ac.cr/ambientales e-mail: revista.ambientales@una.ac.cr

ni uno solo quedará para llorar sobre las tumbas de esta gente que alguna vez fue tan poderosa $y$ albergó tantas esperanzas como la de ustedes.

Pero, ¿para qué afligirnos?, ¿por qué murmurar por el destino de mi gente? Las tribus no son mejores que los individuos que las componen. Los hombres vienen y van como las olas del mar. Una lágrima, un tamanamus [ceremonia religiosa], un lamento fúnebre, y desaparecen para siempre de nuestros ojos anhelantes. Ni el hombre blanco, cuyo dios caminó y conversó con él como de amigo a amigo, está excluido de este destino común. Puede ser que al fin y al cabo sí seamos hermanos. Ya veremos.

Consideraremos la propuesta que nos hace, y le avisaremos cuando hayamos decidido. Si la aceptamos, aquí y ahora pongo una primera condición: que no nos sea negado el privilegio de visitar cuando queramos las tumbas de nuestros antepasados y de nuestros amigos. Cada parte de esta tierra es sagrada para mi gente. Cada ladera, cada valle, cada llanura y cada arboleda están santificadas, sea por un recuerdo afectuoso o por alguna experiencia triste de la tribu.

Hasta las rocas a lo largo de la costa silenciosa, que, en su grandeza solemne, parecen yacer sin pensamiento mientras se cocinan al sol, hasta las rocas se estremecen por los recuerdos que guardan de acontecimientos relacionados con el destino de mi gente, y el mismo polvo bajo los pies responde con más amor a los pasos de nosotros que a los de ustedes, porque contiene las cenizas de nuestros ancestros: nuestros pies descalzos están conscientes de ese contacto amable, porque es suelo enriquecido por la vida de nuestros semejantes.

Los bravos de ébano y las madres orgullosas, las muchachas de corazón alegre y los niños que aqui vivieron tan contentos, y aquellos cuyos nombres ya han sido olvidados, todos seguimos amando estas soledades, pero nuestra profunda fortaleza a la hora en que muere el día se va tornando sombría, por la presencia de los espíritus del crepúsculo. Y cuando haya muerto el último hombre rojo de la tierra y su memoria no parezca sino un mito del hombre blanco, los hijos de los hijos de ustedes no van a estar nunca solos, aunque piensen que lo están, no van a estar solos ni en los campos, ni en la tienda o el almacén, ni en la carretera o en el silencio de las florestas, pues estas orillas van a seguir repletas de los muertos invisibles de mi tribu. No hay en toda la tierra un solo espacio solitario. En la noche, cuando las calles de las ciudades $y$ los pueblos estén en silencio, y ustedes piensen que están desiertas, seguirán repletas de las legiones que una vez llenaron esta bella tierra y la siguen amando. El hombre blanco tampoco va a estar solo nunca. También por eso debe ser justo y tratar bien a mi gente, pues los muertos no son completamente impotentes.

\begin{tabular}{|c|c|c|}
\hline 唶嫼 & (c) (i) () (2) & 352 \\
\hline
\end{tabular}




\section{Revista de CIENCIAS AMBIENTALES Tropical Journal of Environmental Sciences}

Revista de Ciencias Ambientales (Trop J Environ Sci) e-ISSN: 2215-3896

(Enero-Junio, 2021) . Vol 55(1): 345-359 DOI: https://doi.org/10.15359/rca.55-1.10

Open Access: www.revistas.una.ac.cr/ambientales e-mail: revista.ambientales@una.ac.cr

Luego hubo otros oradores, pero yo ya no tomé nota. La réplica del gobernador Stevens fue breve: solo les prometió reunirse con ellos en asamblea general en alguna ocasión futura, para discutir el tratado propuesto. La promesa del Jefe Seattle de adherirse al tratado, en caso de que alguno fuera ratificado, fue observada a la letra, puesto que era un amigo inamovible y fiel del hombre blanco.

Lo de arriba no es sino un fragmento de su discurso, y carece del encanto que le otorgaron en aquella ocasión la gracia y la seriedad del viejo orador de ébano.

\section{El texto de Perry}

Como se indicó en la introducción, el texto de Ted Perry (Figura 3), también recopilado en Gifford (2015), fue escrito en 1970 para la película Home, producida por la Comisión Bautista Sur de Radio y Televisión en 1972.

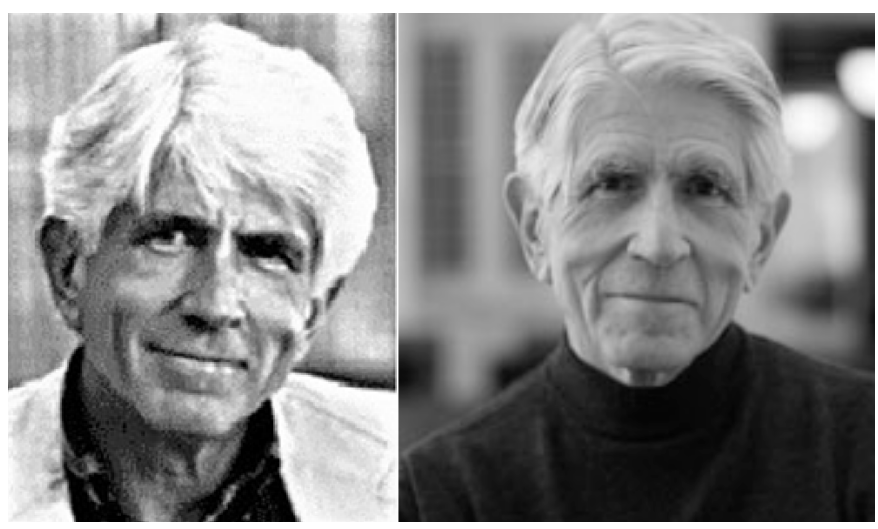

Figura 3. El escritor Ted Perry en dos etapas de su vida.

Figure 3. The writer Ted Perry at different times in his life.

Obviamente, y como él lo reconoce de manera explícita, fue inspirado en el texto de Smith, y alcanza un nivel de lirismo y una riqueza de metáforas, símiles e imágenes que están ausentes en este, como se capta a continuación:

El Gran Jefe de Washington manda a decir que desea comprar esta tierra.

El Gran Jefe nos manda, asimismo, palabras de amistad y de buena voluntad. Es amable, puesto que sabemos que necesita poco nuestra amistad. Y consideraremos su oferta, porque sabemos que, si no vendemos la tierra, el hombre blanco puede venir con armas de fuego y tomarla.

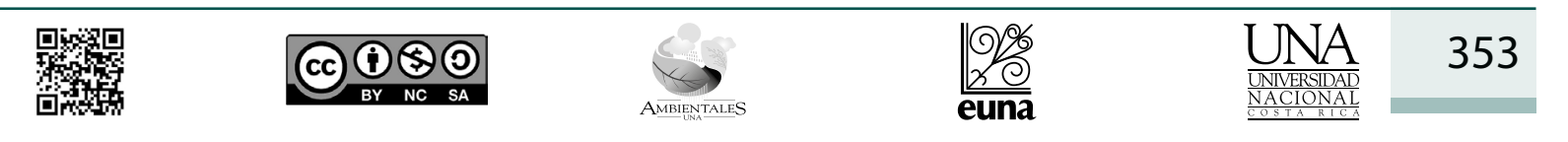




\section{Revista de
CIENCIAS AMBIENTALES Tropical Journal of Environmental Sciences}

Revista de Ciencias Ambientales (Trop J Environ Sci) e-ISSN: $2215-3896$

(Enero-Junio, 2021) . Vol 55(1): 345-359 DOI: https://doi.org/10.15359/rca.55-1.10

Open Access: www.revistas.una.ac.cr/ambientales e-mail: revista.ambientales@una.ac.cr

Pero, ¿cómo comprar o vender el cielo y la calidez de la tierra? Esa noción nos es ajena.

Si no somos dueños de la frescura del aire y de los destellos del agua, ¿cómo puede comprárnoslos?

Decidiremos cuando llegue el momento.

El Gran Jefe de Washington puede confiar en lo que le dice el Jefe Seattle, como confían nuestros hermanos blancos en el cambio de las estaciones. Mis palabras son como las estrellas. No se ponen.

Mi gente considera sagrada cada parte de esta tierra: cada una de las agujas brillantes de los pinos, cada una de las playas arenosas, las nieblas y los claros de los bosques umbríos y también los insectos que zumban, son sagrados en la memoria y en la experiencia de mi gente. La savia que corre por los árboles lleva los recuerdos del hombre rojo.

Cuando los muertos del hombre blanco se van a caminar por entre las estrellas, se olvidan de la tierra en que nacieron. Nuestros muertos nunca se olvidan de esta hermosa tierra, pues es la madre del hombre rojo.

Somos parte de la tierra y la tierra es parte de nosotros. Las flores perfumadas son nuestras hermanas; el venado, el caballo, la gran águila, nuestros hermanos. Las sierras rocosas, la fuerza con que crecen las praderas, el calor del cuerpo de los ponis y también el hombre, todos formamos parte de la misma familia.

Por eso, cuando el Gran Jefe de Washington nos manda a decir que desea comprar nuestra tierra, nos está pidiendo mucho.

El Gran Jefe nos manda a decir que va a reservar un lugar para que podamos vivir cómodamente. Él será nuestro padre y nosotros seremos sus hijos.

Pero eso, ¿será posible alguna vez? Dios, que ama a la gente del Gran Jefe, abandonó a sus hijos rojos, y envía máquinas que le ayudan al hombre blanco en su trabajo y le construye pueblos excelentes. Lo hace cada día más fuerte. Pronto invadirá la tierra de la misma forma en que bajan los ríos en estampida por los cañones tras las lluvias repentinas. Mi gente es la marea que se va: no volveremos nunca.

No. Somos razas aparte: nuestros hijos no juegan juntos y nuestros ancianos no narran las mismas historias. A ustedes Dios los favorece: nosotros somos huérfanos.

\begin{tabular}{|c|c|c|c|c|c|}
\hline 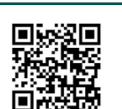 & (c) (1) (\&)(2) & $\Leftrightarrow$ & $\frac{9 \%}{20}$ & $\frac{\text { UNA }}{\frac{\text { UNNERSDDAD }}{\text { NACIONAL }}}$ & 354 \\
\hline
\end{tabular}




\section{Revista de CIENCIAS AMBIENTALES Tropical Journal of Environmental Sciences}

Revista de Ciencias Ambientales (Trop J Environ Sci) e-ISSN: $2215-3896$

(Enero-Junio, 2021) . Vol 55(1): 345-359 DOI: https://doi.org/10.15359/rca.55-1.10

Open Access: www.revistas.una.ac.cr/ambientales e-mail: revista.ambientales@una.ac.cr

Consideraremos, pues, su oferta de comprarnos la tierra. Pero no va a ser sencillo, porque para nosotros estas tierras son sagradas. Disfrutamos de las florestas. No sé: nuestra forma de ser es diferente de la de ustedes.

Esta agua que destella cuando se mueve por los torrentes y los ríos no es solo agua, sino también la sangre de nuestros antepasados. Si le vendemos la tierra, debe recordar que es sagrada y que cada reflejo del agua clara de los lagos narra sucesos y contiene las memorias de mi gente. El murmullo del agua es la voz del padre de mi padre.

Los ríos son hermanos nuestros; nos aplacan la sed. Los ríos transportan nuestras canoas y alimentan a nuestros hijos. Si le vendemos la tierra, debe recordar y enseñarles a sus hijos que los ríos son nuestros hermanos, así como también los de ustedes: en adelante deberán mostrarles la consideración que se le tiene a un hermano.

El hombre rojo siempre se ha replegado ante el avance del hombre blanco, como se disipa el rocío de las montañas ante el sol de la mañana. Las cenizas de nuestros antepasados son sagradas; las sepulturas son tierra sagrada: por eso estas colinas nos han sido consagradas, y también estos árboles, y esta porción de tierra. Sabemos que el hombre blanco no entiende nuestra forma de ser. Piensa que todo pedazo de tierra es igual al que le sigue, porque es como un extraño que llega de noche y se lleva de la tierra solo lo que necesita en ese instante. La tierra no es su hermana, sino su enemiga y, cuando la ha conquistado, sigue su camino. Deja atrás las sepulturas de sus padres: no le importa. Secuestra la tierra de los hijos de la tierra. No le importa. Olvida las sepulturas de sus padres y el patrimonio de sus hijos. Trata a su madre la tierra y a su hermano el cielo como objetos que compra, saquea y vende, como ovejas o cuentas de colores. Terminará devorando la tierra y atrás dejará solo desierto.

No sé, nuestra forma de ser es diferente de la de ustedes. Al hombre rojo se le lastiman los ojos cuando ve las ciudades de ustedes, pero tal vez, se deba a que el hombre rojo es salvaje y no entiende.

No hay un solo lugar tranquilo en las ciudades del hombre blanco. No hay dónde oír cómo se despliegan las hojas en la primavera o el batir de alas de los insectos. Tal vez se deba a que soy un salvaje y no entiendo, pero ese estrépito solo molesta mis oídos. ¿Qué valor tiene la vida si el hombre no puede oír ni el gemido solitario del cuyeo, ni las discusiones nocturnas de las ranas alrededor del estanque? Soy un hombre rojo y no entiendo. El indio prefiere el sonido suave del viento cuando se dispara como un dardo por la faz del estanque, así como el olor del viento mismo, limpio por la lluvia de mediodía o perfumado por las bellotas de los pinos.

\begin{tabular}{|c|c|c|}
\hline 唶嫼 & (c) (i) () (2) & 355 \\
\hline
\end{tabular}




\section{Revista de CIENCIAS AMBIENTALES Tropical Journal of Environmental Sciences}

Revista de Ciencias Ambientales (Trop J Environ Sci) e-ISSN: 2215-3896

(Enero-Junio, 2021) . Vol 55(1): 345-359 DOI: https://doi.org/10.15359/rca.55-1.10

Open Access: www.revistas.una.ac.cr/ambientales e-mail: revista.ambientales@una.ac.cr

El aire le es precioso al hombre rojo, porque todas las cosas, la bestia, el árbol, el hombre, todos comparten el mismo aliento. El hombre blanco parece no darse cuenta del aire que respira, lo mismo que es insensible al hedor del hombre que dura muchos dias agonizando. Pero si le vendemos la tierra, tiene que recordar que el aire es precioso para nosotros, porque el aire comparte el espíritu con toda la vida que mantiene. El viento que le dio el primer hálito a nuestro abuelo también recibe su último suspiro. Y el viento también le debe dar a nuestros hijos el espíritu de la vida. Y si nosotros le vendemos la tierra, debe considerarla aparte y sagrada, como un lugar donde hasta el hombre blanco puede ir a disfrutar del viento, endulzado por las flores de las praderas.

Consideraremos, pues, su oferta de comprarnos la tierra. Si decidimos aceptarla, le pongo una condición: el hombre blanco debe tratar a las bestias de esta tierra como trata a sus hermanos. Soy un salvaje y no conozco ninguna otra forma de comportarme: he visto mil búfalos descomponiéndose en la pradera, abandonados por el hombre blanco, quien los mata desde un tren que pasa. Soy un salvaje y no entiendo cómo el caballo de hierro puede ser más importante que el búfalo que matamos solo para mantenernos vivos.

¿Qué es el hombre sin las bestias? Si desaparecieran todas las bestias, el hombre se moriría de una gran soledad de espíritu. Porque lo que les ocurra a las bestias, poco después le sucede también al hombre. Todas las cosas están relacionadas unas con otras. Lo que le suceda a la tierra, les sucede a los hijos de la tierra.

Deben enseñarles a sus hijos que el suelo que tienen bajo los pies está compuesto por las cenizas de nuestros abuelos. Para que respeten la tierra, díganles a sus hijos que la tierra está enriquecida por las vidas de nuestros familiares. Enséñenles a sus hijos lo que les enseñamos a los nuestros: que la tierra es nuestra madre. Lo que le sucede a la tierra, les sucede a los hijos de la tierra. Si la gente escupe el suelo, se está escupiendo a sí misma.

Sabemos esto: la tierra no le pertenece al hombre, sino que el hombre le pertenece a la tierra. Sabemos esto: todas las cosas están conectadas entre sí, como une la sangre a una familia. Todas las cosas están interrelacionadas.

Lo que le sucede a la tierra, les sucede a los hijos de la tierra. El ser humano no teje la vida, sino que es uno de los hilos. Lo que le haga al tejido, se lo hace a sí mismo.

No: el día y la noche no pueden coexistir.

Nuestros muertos viven en los ríos dulces de la tierra, vuelven con los pasos silenciosos de la primavera, y es su espíritu el que corre con el viento y encrespa la superficie de los estanques.

\begin{tabular}{|c|c|c|}
\hline 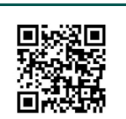 & (c) $\underset{\mathrm{BY}}{\mathrm{N}} \$(\mathrm{O}$ & 356 \\
\hline
\end{tabular}




\section{Revista de CIENCIAS AMBIENTALES Tropical Journal of Environmental Sciences}

Revista de Ciencias Ambientales (Trop J Environ Sci) e-ISSN: 2215-3896

(Enero-Junio, 2021) . Vol 55(1): 345-359 DOI: https://doi.org/10.15359/rca.55-1.10

Open Access: www.revistas.una.ac.cr/ambientales e-mail: revista.ambientales@una.ac.cr

Vamos a analizar por qué desea el hombre blanco comprar esta tierra. Mi gente me pregunta qué es lo que desea comprar el hombre blanco. La idea nos es ajena. ¿Cómo se pueden comprar o vender el cielo, la calidez de la tierra, la levedad del antílope? ¿Cómo es posible que podamos venderles esas cosas, y cómo es posible que las compren ustedes? ¿Es de ustedes la tierra para que ustedes hagan con ella lo que les parezca, solo porque el hombre rojo firma un pedazo de papel y se lo entrega a la gente blanca? Si no somos dueños de la frescura del aire y del destello del agua, ¿cómo nos los pueden comprar? ¿Pueden comprar el búfalo, para que vuelva una vez que hay a caído el último? Pero consideraremos su oferta, porque sabemos que, de no vender la tierra, el hombre blanco puede venir con fusiles y tomarla. Pero somos primitivos y, en el momento pasajero de su fuerza, el hombre blanco piensa que es un dios y dueño de la tierra. ¿Cómo puede un hombre ser dueño de su madre?

Pero vamos a considerar su oferta de comprarnos la tierra. El día y la noche no pueden coexistir. Consideraremos la oferta de ir a la reserva que dispuso usted para mi gente, viviremos aparte, y en paz. Poco importa dónde pasemos el resto de nuestros días. Nuestros hijos han visto a sus padres humillados en la derrota. Nuestros guerreros sienten vergüenza $y$, tras la derrota, pasan ociosos los días y se contaminan el cuerpo con dulces y bebidas fuertes. Poco importa dónde pasemos el resto de nuestros días. No serán muchos. Unas cuantas horas más, unos cuantos inviernos más, y ninguno de los hijos de las grandes tribus que un día habitaron esta tierra y deambulan ahora como bandoleros por los bosques, ninguno quedará para llevar luto por las tumbas de esta gente que una vez fue tan poderosa y tuvo tanta esperanza como la gente de ustedes.

¿Por qué voy a llevar luto por la desaparición de mi gente? Las tribus están compuestas de hombres, nada más. Los hombres vienen y se van, como las olas del mar.

Ni el hombre blanco, cuyo Dios camina y habla con él como un amigo con otro, ni la gente blanca, están exentos del destino común. Después de todo, puede que resultemos hermanos: ya se verá. Pero sí sabemos una cosa que tal vez el hombre blanco descubra algún día: nuestro Dios es el mismo.

Usted puede pensar que posee a Dios como desea poseer nuestra tierra, pero no es así. Es el Dios de todos los hombres y su compasión es la misma, tanto para el hombre rojo como para el blanco. Para él, esta tierra es preciosa, y dañarla es acumular desprecio sobre el Creador. También los blancos pasarán, a lo mejor hasta más rápido que todas las otras tribus. Si continúan contaminando su cama, una noche se sofocarán en sus propios desechos.

Cuando perezca, el hombre blanco brillará intensamente, fulgurante por la fuerza del Dios que lo trajo a esta tierra y quien, por algún designio especial, le dio dominio sobre ella y sobre

\begin{tabular}{|c|c|c|}
\hline 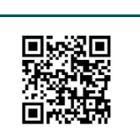 & (C) (i) () () & 357 \\
\hline
\end{tabular}




\section{Revista de CIENCIAS AMBIENTALES Tropical Journal of Environmental Sciences}

Revista de Ciencias Ambientales (Trop J Environ Sci) e-ISSN: $2215-3896$

(Enero-Junio, 2021) . Vol 55(1): 345-359 DOI: https://doi.org/10.15359/rca.55-1.10

Open Access: www.revistas.una.ac.cr/ambientales e-mail: revista.ambientales@una.ac.cr

el hombre rojo. Para nosotros, ese destino es un misterio, porque no entendemos cómo va a ser cuando todos los búfalos estén muertos, domesticados los caballos salvajes, los rincones secretos de las florestas cargados del olor de muchos hombres, y la vista a las colinas obnubilada por los alambres parlantes del telégrafo.

¿Adónde se fue la espesura? ¿Qué se hizo el águila? Y, ¿cómo es despedirse del leve poni y de la caza? Será el final de la vida y el inicio de la mera supervivencia.

Por algún designio especial, Dios les dio a ustedes dominio sobre las bestias, las florestas y la gente roja, pero ese destino le resulta un misterio para el hombre rojo.

Tal vez podríamos entender si supiéramos qué sueña el hombre blanco, de qué esperanzas les habla a sus hijos en las largas noches de invierno, qué visiones les graba a fuego en la mente para que las deseen al día siguiente. Pero nosotros somos salvajes, no podemos ver los sueños del hombre blanco. Y, porque no los podemos ver, seguimos nuestra propia senda. Porque, por sobre todo lo demás, tenemos en mucho el derecho que tiene cada hombre de vivir como desea, por más lejos que esté de lo que desean sus hermanos. Hay muy poco en común entre nosotros.

Así es que vamos a considerar la oferta que usted nos hace, de comprarnos la tierra. Si aceptamos, será para asegurarnos la reserva que nos ha prometido. Allí tal vez podamos vivir como queramos los breves días que nos restan. Cuando el último hombre rojo haya desaparecido de la tierra, y su memoria no sea sino la sombra de una nube que pasa a través de la pradera, estas costas y estas florestas todavía contendrán los espíritus de mi gente. Porque amamos esta tierra como el recién nacido ama los latidos del corazón de su madre.

Si les vendemos la tierra, ámenla como la hemos amado nosotros. Cuídenla como la hemos cuidado nosotros. Mantengan la memoria de esta tierra tal y como era cuando la tomaron.

Y, con toda su fuerza, con toda su mente, con todo su corazón, presérvenla para sus hijos, y ámenla, como nos ama Dios a todos.

Sabemos una cosa: nuestro Dios es el mismo Dios. Para él, esta tierra es preciosa. Ni siquiera el hombre blanco está exento del destino común. Después de todo, puede que sí seamos hermanos. Ya veremos.

\section{Colofón}

Presentadas las dos versiones tal cuales, quedan disipadas las dudas acerca del contenido exacto y la paternidad de tan controvertida alocución. Y, al reconocer esta situación, confiamos en que, ahora que se conocen ambas en español - traducidas por una misma persona, para

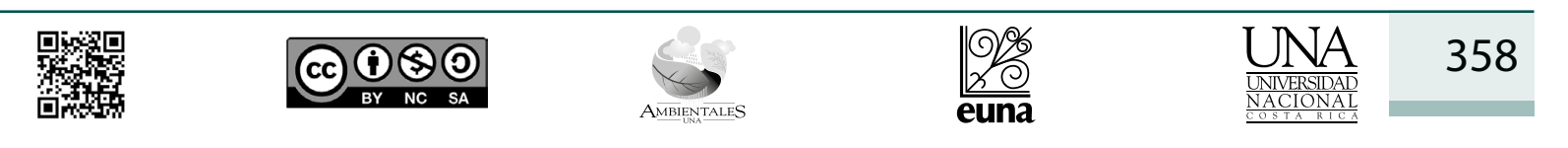




\section{Revista de CIENCIAS AMBIENTALES Tropical Journal of Environmental Sciences}

Revista de Ciencias Ambientales (Trop J Environ Sci) e-ISSN: 2215-3896

(Enero-Junio, 2021) . Vol 55(1): 345-359 DOI: https://doi.org/10.15359/rca.55-1.10

Open Access: www.revistas.una.ac.cr/ambientales e-mail: revista.ambientales@una.ac.cr

evitar sesgos idiomáticos-, quienes utilicen esta información con fines académicos o educativos, lo hagan con la mayor objetividad posible.

Al final de cuentas, e independientemente de que el autor fuera el Jefe Seattle, Smith o Perry, lo importante y esencial es que el mensaje conservacionista derivado de la primigenia relación entre el hombre y la tierra ahí manifiesto, propio de la cosmovisión indígena, nos sirva como inspiración y guía para las luchas por la protección de los preciados y tan amenazados recursos naturales que hacen posible la vida en nuestro planeta.

\section{4. Ética y conflicto de intereses}

Las personas autoras declaran que han cumplido totalmente todos los requisitos éticos y legales pertinentes, tanto durante el estudio como en la producción del manuscrito; que no hay conflicto de interés de ningún tipo; y que están totalmente de acuerdo con la versión final editada del artículo.

\section{Agradecimientos}

A Ted Perry, hoy con 83 años de edad, por responder con gran gentileza a mi solicitud para esclarecer la paternidad de la discutida alocución. A Silvia Kruse Quirós, por la calidad con que efectuó la traducción de ambos textos. A Theresa White, por revisar el resumen en inglés.

\section{Referencias}

Anónimo. (1989). The gospel of Chief Seattle is a hoax. Environmental Ethics 11(3): 195-196. https://doi.org/10.5840/enviroethics19891139

Gifford, E. (2015). The many speeches of Chief Seattle (Seathl): Manipulation of the record on behalf of political, religious and environmental causes. CreateSpace Independent Publishing Platform, North Charleston, South Carolina. 204 p.

Hilje, L. (2000). ¿Engaño literario? Diario La Nación. 4 de octubre de 2000. p. 14A.

Obregón, R. (1991). Costa Rica y la guerra contra los filibusteros. Museo Histórico Cultural Juan Santamaría. Alajuela, Costa Rica. 409 p.

\begin{tabular}{|c|c|c|}
\hline 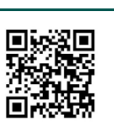 & (c) (1) () () (2) & 359 \\
\hline
\end{tabular}

